\title{
Ureter ectópico extramural em um cão Labrador Retriever: relato de caso
}

\author{
[Ectopic ureter extramural in a Labrador Retriever dog: a case report]
}

\author{
M.R. Lempek ${ }^{1}$, A.C. Sapia ${ }^{2}$, T. Gobbi ${ }^{3}$, R.C. Valadares ${ }^{1}$, J.M.C. Menezes ${ }^{1}$, B.A. Soares ${ }^{1}$, \\ D.B. Souza ${ }^{1}$, R.A. Carneiro ${ }^{1}$, M.M. Melo ${ }^{1}$, J.C.C. Veado ${ }^{1}$, R.C.S. Tôrres ${ }^{1}$ \\ ${ }^{1}$ Universidade Federal de Minas Gerais - UFMG, Belo Horizonte, MG \\ ${ }^{2}$ Instituto Federal de Educação, Ciência e Tecnologia Catarinense - IFC, Araquari, SC \\ ${ }^{3}$ Universidade Federal de Goiás - UFG, Goiânia, GO
}

\begin{abstract}
RESUMO
A ectopia ureteral é uma enfermidade congênita que se caracteriza quando um ou ambos os ureteres apresentam-se inseridos fora do seu local anatômico, com a inserção ocorrendo no útero, no colo da bexiga, na uretra ou na vagina, devido a uma diferenciação anormal dos ductos mesonéfricos e metanéfricos. Nos machos, a inserção pode ocorrer também nos ductos deferentes e na próstata. A incontinência urinária é o sinal clínico mais comumente associado ao ureter ectópico. O presente relato descreve um caso de ureter ectópico extramural unilateral, em um cão da raça Labrador Retriever de sete anos de idade, corrigido cirurgicamente, e mostra a importância dos exames radiográfico contrastado e ultrassonografia.
\end{abstract}

Palavras-chave: cão, incontinência urinária, ureter ectópico

\section{ABSTRACT}

Ureteral ectopia is a congenital disease that is characterized when one or both ureters are shown inserted outside their anatomic site, with the possible insertion in the uterus, bladder neck, the urethra or vagina due to abnormal differentiation of ducts mesonephrics and metanephrics. In males the insertion can also occur in the vas deferens and prostate. Urinary incontinence is the most common clinical sign associated with ectopic ureter. This report describes a case of unilateral extramural ectopic ureter in a dog of the Labrador Retriever breed at seven years old surgically corrected, and shows the importance of contrast radiographic examination and ultrasound.

Keywords: dog, urinary incontinence, ectopic ureter

\section{INTRODUÇÃO}

A ectopia ureteral é uma anomalia congênita, resultante de uma falha na diferenciação dos ductos mesonéfricos e metanéfricos durante a embriogênese, caracterizada por uma localização anormal do segmento terminal, de um ou de ambos os ureteres, fora da região do trígono vesical (Osborne et al., 1995; Costa Neto et al., 2011).

As inserções ectópicas frequentes incluem o colo da bexiga, a uretra proximal ou medial, o útero ou a vagina nas fêmeas e a uretra prostática nos machos (Mcloughlin, 2008). Dessa forma, podem-se distinguir anatomicamente dois tipos de ureter ectópico, de acordo com seu trajeto até o orifício final, em intramural e extramural. $\mathrm{O}$ intramural se localiza na superfície dorsal ou dorsolateral da bexiga, passando geralmente pela submucosa, enquanto no extramural o ureter desvia completamente desta (Prado et al., 2014; Balohg et al., 2015).

Há relatos de ureteres ectópicos em gatos, ratos, cavalos, humanos e cães, de transmissão genética e etiologia idiopática. Raças caninas como

Recebido em 14 de outubro de 2015

Aceito em 20 de abril de 2016

E-mail: marthin.cardiovet@gmail.com 
Labrador Retriever, Golden Retriever, Husky Siberiano, West Highland White Terrier e Poodle Toy são mais predispostas (Mcloughlin e Chew, 2000). Entretanto, pesquisas que determinem a ocorrência e a frequência dessa enfermidade no Brasil não foram relatadas (Costa Neto et al., 2011).

O principal sinal clínico associado ao ureter ectópico é a incontinência urinária, pelo fato de o ureter desembocar diretamente na uretra ou por mau funcionamento dos esfíncteres ureterais interno e/ou externo (Mcloughlin e Chew, 2000; Ho et al., 2011). O ureter ectópico é uma patologia diagnosticada precocemente com maior frequência em cadelas jovens, enquanto nos machos o diagnóstico costuma ser mais tardio (Reichler et al., 2012). Eczema vulvar com hiperpigmentação e hipotricose bem como dermatite na região ventral do abdome e infecção urinária bacteriana secundária também são frequentemente observados (Mcloughlin, 2008).

A localização do segmento terminal do ureter ectópico é recomendada, tendo significância diagnóstica e terapêutica (Osborne et al., 1995). Os métodos de diagnóstico indicados são a ultrassonografia e a radiografia, porém, devido à dificuldade de visibilização em exames radiográficos simples, a urografia excretora é mais indicada, pois permite uma melhor avaliação dos ureteres e da junção ureterovesical (Espada et al., 2006).

A correção cirúrgica consiste no tratamento de escolha, sendo a técnica escolhida dependente do número de ureteres ectópicos, do local da terminação, do seu funcionamento e da presença de anomalias concomitantes (Getman et al., 2005).

Este trabalho objetiva relatar um caso de ureter ectópico extramural em um cão da raça Labrador Retriever de sete anos de idade, corrigido cirurgicamente, além de abordar os aspectos diagnósticos e terapêuticos da enfermidade.

\section{CASUÍSTICA}

Um cão, macho, não castrado, da raça Labrador Retriever, com sete anos de idade e peso corporal de $35 \mathrm{~kg}$, foi atendido no Hospital Veterinário da Universidade Federal de Minas Gerais (HV UFMG), pelo Serviço de Nefrologia e Urologia Veterinárias, com queixa de incontinência urinária há três meses.

Ao exame físico geral, o cão apresentava escore de condição corporal (ECC) ideal: normohidratado, mucosas normocoradas, tempo de preenchimento capilar (TPC) inferior a dois segundos, frequências cardíaca e respiratória dentro dos valores de referência e temperatura de $38^{\circ} \mathrm{C}$.

Como exames complementares de rotina, foram realizados: hemograma completo, perfil bioquímico, ultrassonografia abdominal e cistocentese para a realização de urinálise, urocultura e relação proteína/creatinina urinária (RPC).

No hemograma e no perfil bioquímico, os valores apresentaram-se dentro da faixa de referência de normalidade para cães. A urinálise revelou um discreto aumento bacteriano $(+)$, confirmado pela urocultura, caracterizando quadro de cistite bacteriana.

$\mathrm{Na}$ ultrassonografia abdominal, verificou-se hidronefrose do rim direito grau II e pelve discretamente dilatada com presença de líquido (Fig. 1), ureter dilatado $(12,1 \mathrm{~mm})$, tortuoso e com inserção na uretra proximal na região cranial à próstata, sugestivo de ureter direito ectópico extramural (Fig. 2).

Para a certificação da suspeita diagnóstica, realizou-se urografia excretora. Confirmou-se o diagnóstico ultrassonográfico de ureter ectópico extramural direito, além da melhor visibilização da inserção do ureter em uretra proximal cranial à próstata (Figs. 3, A e B e 4).

Em razão do diagnóstico de ureter ectópico extramural direito, o paciente foi submetido ao tratamento cirúrgico. Em adição, uma vez constatada cistite bacteriana por Escherichia coli, foram prescritos amoxicilina com clavulanato de potássio $(20 \mathrm{mg} / \mathrm{kg})$, a cada 12 horas, durante 14 dias, e omeprazol $(1 \mathrm{mg} / \mathrm{kg})$, a cada 24 horas, durante o mesmo período. 


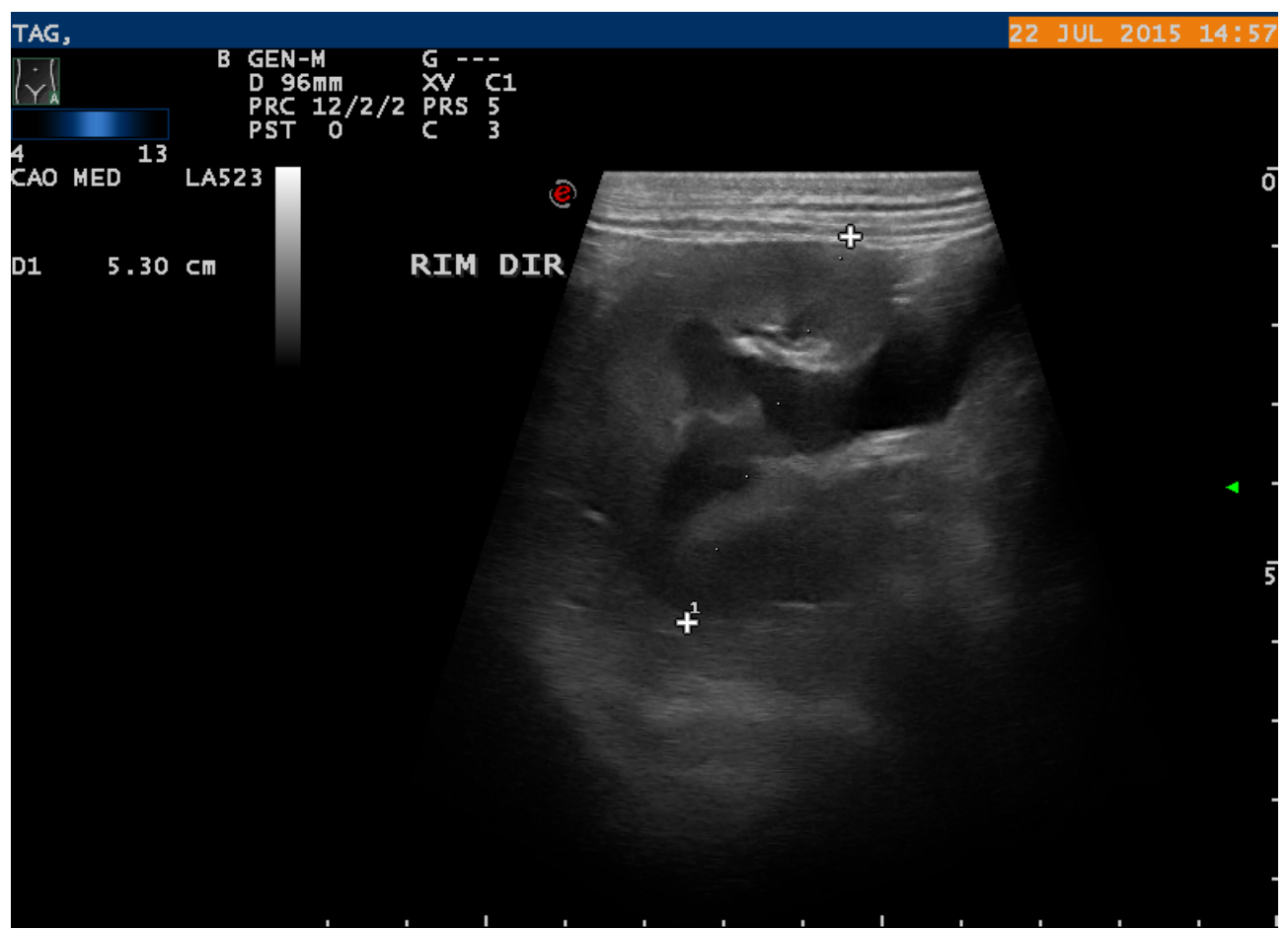

Figura 1. Ultrassonografia do rim direito evidenciando hidronefrose de grau II e dilatação pélvica, em cão da raça Labrador Retriever de sete anos de idade, $35 \mathrm{~kg}$ de peso corporal e não castrado.

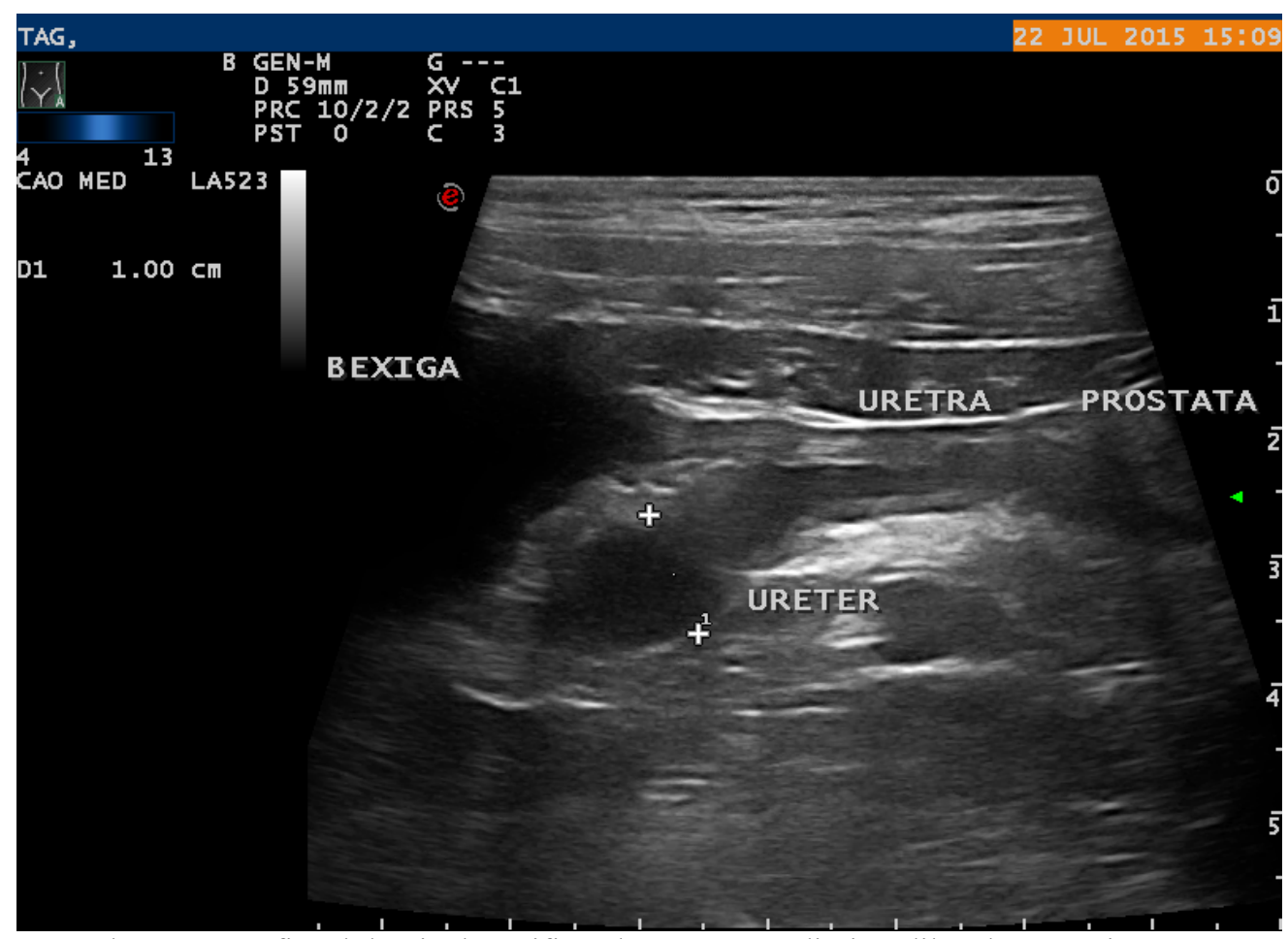

Figura 2. Ultrassonografia abdominal verificando-se ureter direito dilatado com inserção na uretra prostática cranial, sugestivo de ureter ectópico extramural, em cão da raça Labrador Retriever de sete anos de idade, $35 \mathrm{~kg}$ de peso corporal e não castrado. 

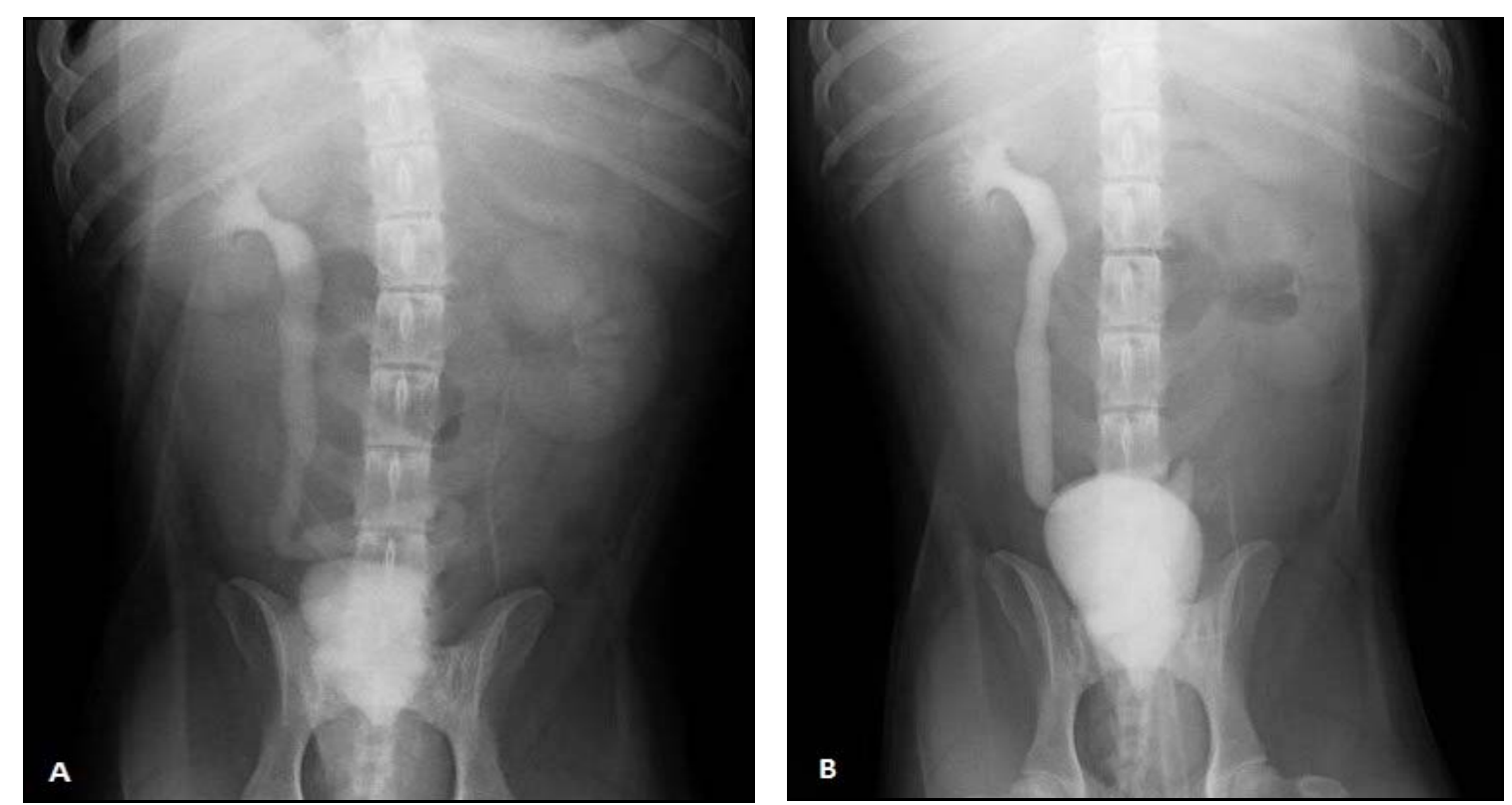

Figura 3. Radiografia ventrodorsal da urografia excretora nos tempos cinco minutos (A) e 30 minutos (B), evidenciando-se a dilatação ureteral direita, em cão da raça Labrador Retriever de sete anos de idade, $35 \mathrm{~kg}$ de peso corporal e não castrado.

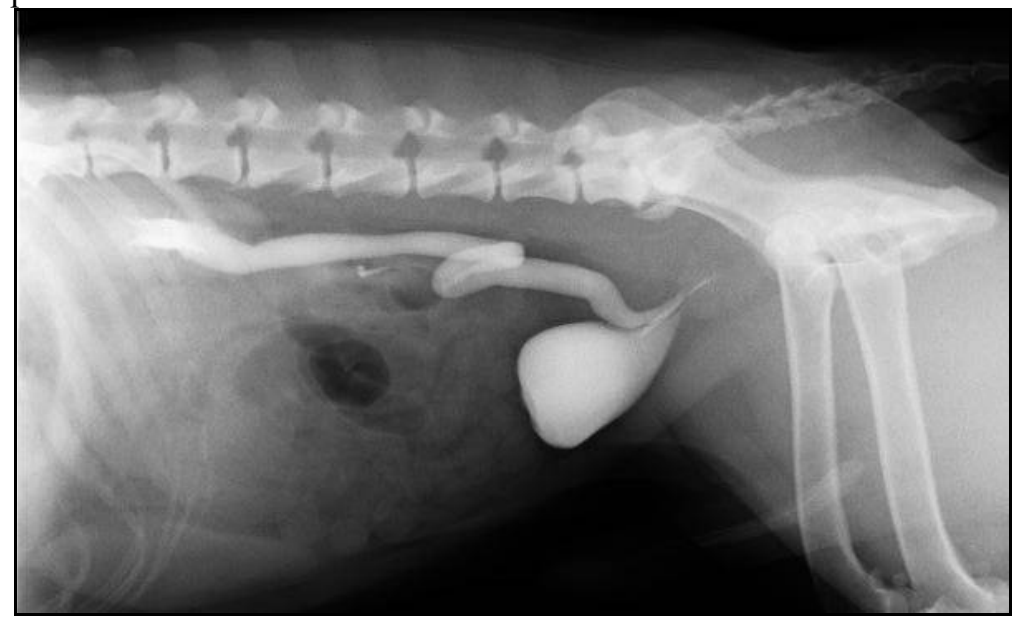

Figura 4. Radiografia laterolateral da urografia excretora (30 minutos), na qual se observa a inserção ureteral direita na uretra em região prostática cranial, em cão da raça Labrador Retriever de sete anos de idade, $35 \mathrm{~kg}$ de peso corporal e não castrado.

Realizou-se laparotomia na linha média ventral retroumbilical desviando do pênis em seu lado direito. Após a identificação do hidroureter direito (Fig. 5A), foi realizada dissecação de sua aderência com a serosa da bexiga até sua entrada na uretra proximal à próstata, seguida de sua ligadura e ressecção.

Logo após, realizou-se cistotomia ventral, e uma pequena incisão foi feita na mucosa da bexiga, próximo ao seu ápice do lado direito. Em seguida, utilizou-se uma pinça hemostática
Halsted para completar a perfuração até a serosa, quando se tracionou a extremidade livre do ureter direito para dentro da bexiga. O ureter foi espatulado e sua mucosa foi suturada com a mucosa da bexiga, em padrão simples, separada, utilizando-se poliglecaprone 4-0 (Fig. 5B).

A cistorrafia foi realizada em duas camadas com poliglecaprone 3-0, sendo a primeira simples contínua e a segunda Lembert. Para a laparorrafia, utilizou-se poliglecaprone $0 \mathrm{em}$ padrão Reverdin. O espaço morto foi reduzido 
com poliglecaprone 3-0 em padrão simples contínuo. A dermorrafia foi realizada utilizandose nylon 3-0 em padrão Wolf.

Após correção cirúrgica, o animal apresentou melhora do quadro de incontinência urinária.
Trinta dias depois da cirurgia, o paciente foi submetido novamente à urografia excretora para se verificar o calibre do ureter. Observou-se significativa redução do diâmetro e pouco acúmulo de contraste no ureter direito (Fig. 6-A e B).

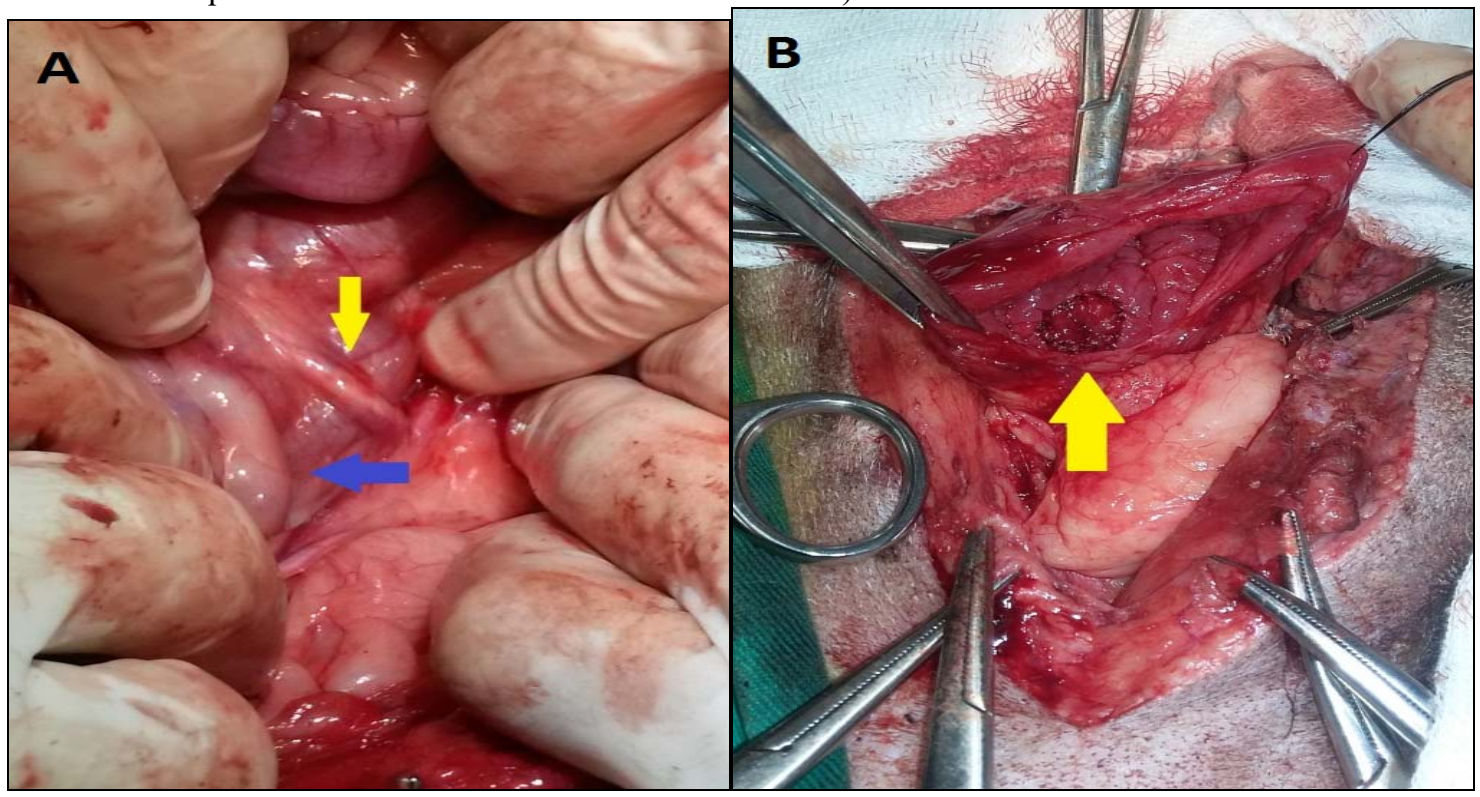

Figura 5. Aspectos cirúrgicos observados em cão da raça Labrador Retriever de sete anos de idade, $35 \mathrm{~kg}$ de peso corporal e não castrado. A - Visibilização do ureter ectópico direito dilatado (seta azul) e ureter esquerdo normal (seta amarela). B - Cistotomia vesical para inserção cirúrgica do ureter ectópico esquerdo em região do trígono vesical, realizado novo óstio uretral (seta amarela).
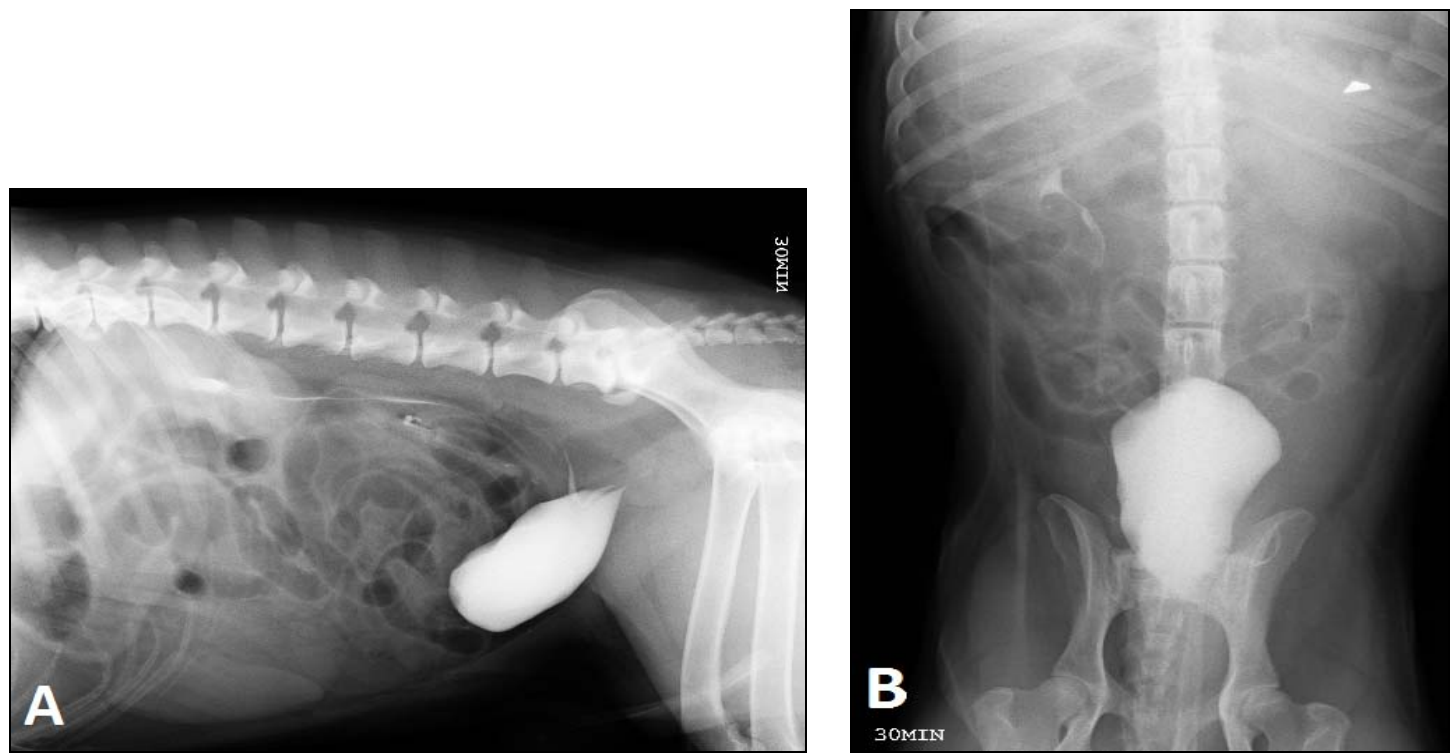

Figura 6. Urografia excretora em cão da raça Labrador Retriever de sete anos de idade, $35 \mathrm{~kg}$ de peso corporal e não castrado. A - Observa-se redução do calibre do ureter direito com pouco acúmulo de contraste. B - Verifica-se a diminuição do refluxo do contraste no ureter direito, demonstrando melhor vazão da urina para bexiga, além da redução considerável da hidronefrose. 


\section{DISCUSSÃO}

Por ser resultante de uma diferenciação dos ductos mesonéfricos e metanéfricos durante a embriogênese (Osborne et al., 1995; Costa Neto et al., 2011), o presente relato de ectopia ureteral unilateral extramural é raro.

A raça Labrador Retriever está entre as mais predispostas ao desenvolvimento dessa anomalia (Mcloughlin e Chew, 2000). Apesar de as alterações ureterais acometerem mais fêmeas que machos, numa proporção de 25:1, há uma significante diferença de acordo com a classificação, em que extramurais afetam mais machos que fêmeas, podendo ter a inserção na vesícula urinária ou na uretra prostática, conforme observado neste relato (Novellas et al., 2013; Fritsche et al., 2014).

Diferenças genéticas entre as raças mais afetadas podem estar associadas a determinados isolamentos geográficos, provavelmente responsáveis pelas divergências entre os sexos encontrados (Reichler et al., 2012). Dessa forma, no Brasil, é recomendada a realização de estudos genéticos sobre a ocorrência dessa patologia, tentando criar perfis de prováveis portadores da anomalia para auxiliar no diagnóstico precoce (Osborne et al., 1995).

O sinal clínico mais evidente é a incontinência urinária. Nos machos, esse sinal pode ser subdetectado devido à presença de um mecanismo de esfíncter uretral mais eficiente e uma uretra mais longa, quando comparados às fêmeas (Osborne et al., 1995; Mcloughlin, 2008; Novellas et al., 2013). Por esse motivo, muitos animais são diagnosticados tardiamente, por manifestarem sinais clínicos tardios, como é o caso deste animal, cujo diagnóstico foi dado somente com sete anos de idade.

A ultrassonografia é um método eficaz para visibilização não invasiva das anormalidades decorrentes da ectopia ureteral (Osborne et al., 1995; Novellas et al., 2013), podendo ser considerada um método de diagnóstico definitivo (Mcloughlin e Chew, 2000). Também é utilizada na detecção de anormalidades associadas, como hidronefrose ou hidroureter (Noevellas et al., 2013). Entretanto, observou-se que a radiografia contrastada foi fundamental na identificação e na localização exata da terminação ureteral e em sua classificação como intra ou extramural (Espada et al., 2006; Novellas et al., 2013), auxiliando, dessa forma, na escolha da técnica cirúrgica. A combinação da ultrassonografia com a urografia excretora permitiu a visibilização das alterações anatômicas do trato urinário, sendo métodos eficientes para detecção de ureter ectópico.

O ureter ectópico tem sido comumente associado a múltiplas anomalias do trato urinário, como hidronefrose, hidroureter e ureter tortuoso (Mcloughlin e Chew, 2000), conforme verificado no caso descrito.

O estado reprodutivo de machos e fêmeas influencia na predisposição de cães aos sinais clínicos, visto que a remoção das gônadas resulta em redução da pressão de fechamento uretral e, consequentemente, em incontinência urinária (Novellas et al., 2013; Fritsche et al., 2014). No presente relato, o resultado favorável para $o$ estado de continência pós-operatória pode ser explicado pelo fato de se tratar de um cão não castrado. Entretanto, a infecção bacteriana do trato urinário inferior pode causar instabilidade do músculo detrusor da bexiga e incontinência urinária (Mcloughlin, 2008).

Embora a correção cirúrgica de ureter ectópico tenha um prognóstico favorável, há uma elevada taxa de complicações pós-operatórias (Reichler et al., 2012), as quais não foram observadas no paciente descrito.

Ureteres ectópicos constituem uma anormalidade congênita hereditária, que deve ser diagnosticada precocemente pelo médico veterinário e para a qual devem ser traçadas alternativas terapêuticas, com intervenção cirúrgica e correção dos ureteres ectópicos. A suspeita de ectopia ureteral congênita unilateral foi levantada pela presença de incontinência urinária, sendo confirmada pela ultrassonografia e urografia excretora.

\section{CONCLUSÕES}

Qualquer animal que apresente incontinência urinária, independentemente da idade, deve ser investigado quanto à presença de um possível ureter ectópico. Embora de ocorrência rara, animais adultos, como no caso descrito, podem apresentar sinais clínicos sugestivos dessa máformação, mesmo após alguns anos de idade. O diagnóstico pode ser confirmado por diferentes 
modalidades de exames de imagem, como a ultrassonografia e a urografia excretora. A urografia excretora possibilita a melhor visibilização da inserção do ureter no trígono vesical, permitindo então a identificação de sua inserção ectópica. Essa técnica de radiografia contrastada contribui, ainda, para a escolha da técnica cirúrgica mais apropriada. O prognóstico dos pacientes que são submetidos à intervenção cirúrgica é favorável, como no caso relatado. Quanto antes se realizar o procedimento cirúrgico, melhor a recuperação do paciente e menores as chances de ocorrências de alterações como hidroureter e hidronefrose.

\section{REFERÊNCIAS}

BALOGH, O.; DEGRANDI, F.; HASSIG, M.; REICHLER, I.M. Validation of screening examinations of the ureteral orifices in dogs: comparison of ultrasonography with dissection. Res. Vet. Sci., v.101, p.199-205, 2015.

COSTA NETO, J.M.; SILVA, A.E.; MARTINS FILHO, E.F. et al. Ectopia ureteral em cães: relato de dois casos. Arq. Ciênc. Vet. Zool. v.14, p.151-156, 2011.

ESPADA, Y.; NOVELLAS, R.; GOPEGUI, R.R. Renal ultrasound in dogsandcats. Vet. Res. Commun., v.30, p.133-137, 2006.

FRITSCHE, R.; DOLF, G.; SCHELLING, C. et al. Inheritance of ectopic ureters in entlebucher mountain dogs. J. Anim. Breed. Genet., v.131, p.146-152, 2014.
GETMAN, L.M., ROSS, M.W., ELCE, Y.A. Bilateral ureterocystostomy to correct left ureteral atresia and right ureteral ectopia in a 8 month old standardbred filly. Vet. Surg., v.34, p.657-661, 2005.

HO, L.K.; TROY, G.C.; WALDRON, D.R. Clinical outcomes of sugically managed ectopic ureters in 33 dogs. J. Am. Anim. Hosp. Assoc., v.47, p.196-202, 2011.

MCLOUGHLIN, M.A. Doenças do sistema urogenital. In: BIRCHARD, S.J.; SHERDIN, R.G. Manual saunders, clínica de pequenos animais. São Paulo: Roca, 2008. p.906-907.

MCLOUGHLIN, M.A.; CHEW, D.J. Diagnosis and surgical management of ectopic ureters. Clin. Tech. Small Anim. Pract., v.15, p.17-24, 2000.

NOVELLAS, R.; STONE, J.; PRATSCHKE, K.; HAMMOND, G. Duplicated ectopic ureter in a nine-year-old Labrador. J. Small Anim. Pract., v.54, p.386-389, 2013.

OSBORNE, C.A.; JOHNSTON, G.R.; KRUGER, J.M. Ectopia ureters and ureteroceles. In: OSBORNE, C.A.; FINCO, D.R. Canine and feline nephrology and urology. [Philadelphia]: Williams \&Wilkins, 1995. p.608-620.

PRADO, T.D.; GOUVEIA, T.C.; AMARAL, A.S.Z.; RIBEIRO, R.G. Ureteres ectópicos em cães. Agrar. Acad., v.1, p.170-177, 2014.

REICHLER, I.M.; SPECKER, C.E.; HUBLER, M. et al. Ectopic ureters in dogs: Clinical features, surgical tecniques and outcome. Vet. Sug., v.41, p.515-522, 2012. 